\title{
La actualización de los mitos fundacionales de la nación en el cine histórico- folclórico argentino, la obra del grupo Cine Liberación y el cine histórico cubano
} (1968 - 1976)

Ignacio del Valle Dávila*

\section{Resumo}

No final dos anos sessenta, ocorreu uma eclosão do cinema folclórico-histórico na Argentina e em Cuba. No primeiro caso, isso se deu principalmente devido ao interesse da ditadura de Onganía em utilizar os mitos fundadores da nação como uma metáfora legitimadora do regime. Contrários a essa tendência, o Grupo Cine Liberación elaborou representações desses relatos que buscavam adaptá-los à contingência, especialmente nos filmes La hora de los hornos (1968) e Los hijos de Fierro (1975). Em Cuba, o centenário da Guerra Grande (1868-1878) e a maior rigidez ideológica em matéria cultural durante o Quinquênio Gris (1971-1976) levaram a que se fomentasse a produção de um cinema histórico que representava a Revolução de 1959 como o produto de um século de luta. Os cineastas cubanos e Cine Liberación coincidiram em sua busca por renovar a forma de representação cinematográfica da História, enquanto o cinema comercial argentino apostou em adaptações distantes desse revisionismo.

Palavras-chave: cinema histórico, legitimação, mitos nacionais.

\section{Résumé}

À la fin des années soixante s'est produit en Argentine et Cuba une éclosion du cinéma folklorique-historique. Dans le premier cas, ceci est dû principalement à l'intérêt de la dictature d'Onganía à se servir des mythes fondateurs de la nation avec l'objectif d'élaborer des métaphores légitimatrices du régime. Face à cela, Grupo Cine Liberación a élaboré des représentations de ces récits tout en cherchant à les adapter à la contingence, notamment dans les films L'heure des brasiers (1968) et Les fils de Fierro (1975). À Cuba le centenaire de la Guerre des dix ans (1968-1878) ainsi qu'une plus grande rigidité idéologique dans le domaine culturel pendant le Quinquennat Gris (1971-1976), ont conduit à l'encouragement de la production d'un cinéma historique où la révolution de 1959 est représentée comme la conclusion d'un siècle de lutte. Les cinéastes cubains et Cine Liberación ont partagé leur intérêt de renouveler les

\footnotetext{
* Doctor Université Toulouse II. E-mail: elvalledeignacio@gmail.com.
}

Revista Eletrônica da ANPHLAC, n.14, p. 241-264, jan./jun. 2013. http://revista.anphlac.org.br/index.php/revista 
représentations cinématographiques de l'Histoire, tandis que le cinéma commercial argentin a misé sur des adaptations éloignées du révisionnisme.

Mots-clés: cinéma historique, légitimation, mythes nationaux.

\begin{abstract}
At the end of the sixties, there was a growth of historical-folkloric cinema in Argentina and Cuba. In the first case, it happened mainly because of the interest of the Onganía's dictatorship in making use of the nation's founding myths to develop metaphors to legitimize this regime. On the other hand, Grupo Cine Liberación elaborated representations of these narratives trying to adapt them to the contingency, especially in the movies The hour of the furnaces (1968) and Los hijos de Fierro (1975). In Cuba, the centenary of the War of ten years (1868-1878), as well as an increase of ideological rigidity in the cultural domain during the Grey Quinquennium (1971-1976), encouraged the production of a historical cinema where the revolution of 1959 has been represented as the conclusion of a century of struggle. Cuban filmmakers and Cine Liberación shared their interest in renewing the filmic representations of History, whereas the Argentinean commercial cinema supported adaptations far from this revisionism.
\end{abstract}

Keywords: historical cinema, legitimization, national myths

\title{
Introducción
}

A fines de los años sesenta, agotado el proyecto desarrollista de sustitución de importaciones, los países latinoamericanos enfrentaban un contexto político y social marcado por la Revolución cubana y los proyectos de liberación Tricontinental. Frente a los movimientos de "liberación nacional" se desencadenaría una serie de golpes de estado "preventivos" inspirados por la teoría de la Seguridad Nacional. A uno y otro lado de un espectro político crecientemente polarizado se invocaba -aunque con connotaciones opuestas- la idea de "refundar" la nación y de emprender una “revolución”. En el campo cinematográfico, como en el resto de los campos artísticos, los diferentes proyectos sociales se disputaron el control de las representaciones simbólicas de la nación y de los imaginarios colectivos, mediante propuestas artísticas antagónicas. Los agentes políticos y sociales buscaron legitimarse ideológicamente autodenominándose como herederos de un pasado nacional glorioso -particularmente de los procesos de Independencia- y de las tradiciones folklóricas del siglo XIX. Así

Revista Eletrônica da ANPHLAC, n.14, p. 241-264, jan./jun. 2013. http://revista.anphlac.org.br/index.php/revista 
comenzó a ganar importancia a fines de los años sesenta un cine que aludía al nacimiento del estado nación. Se trató en buena medida de filmes donde se desarrollaban alegorías teleológicas: en ellos una corriente política específica -o un régimen- se insinuó como depositaria incorruptible de los valores que emanan de la historia y la tradición nacional. En otros casos la alegoría histórica-folklórica fue usada para eludir la censura.

Este tipo de producción hace explícito el interés que ha despertado el cine como medio de difusión pedagógica de idearios políticos, o si se prefiere, como forma artística extremadamente efectiva en la tarea de fomentar y compartir masivamente imaginarios sociales - "representaciones colectivas, ideas-imágenes de la sociedad" (BACZKO, 1984, p. 8)- asociados a un ideal político. La creación de representaciones globales de un colectivo -incluidos sus mitos y utopías- es de vital importancia para darle una identidad, elaborar modelos formadores o legitimar un poder. El control de estas representaciones es, por ello mismo, fundamental para la estabilidad del poder:

El impacto de los imaginarios sociales sobre las mentalidades depende en gran medida de su difusión, de los circuitos y medios de los que dispone. Para lograr la dominación simbólica, es de capital importancia controlar esos medios que son instrumentos de persuasión, de presión, de inculcación de valores y creencias. Así todo poder aspira a tener un papel privilegiado en la emisión de los discursos que vehiculan los imaginarios sociales, a la vez que busca guardar cierto control sobre sus circuitos de difusión (BACZKO, 1984, p. 36).

Trataremos de analizar aquí el desarrollo de este fenómeno a fines de los años sesenta y principios de los setenta en Argentina y Cuba. El interés de analizar ambas cinematografías obedece, principalmente a tres razones: en primer lugar se trata de un fenómeno que se produce en los dos países más o menos al mismo tiempo; en segundo lugar, son los países donde el cine histórico-folklórico alcanzó mayor desarrollo en cuanto a número de producciones e inversión y donde tuvo más éxito entre el público; por último, en ambos países este cine fue fomentado por los aparatos del estado, tuvo una finalidad didáctica y sirvió para legitimar el orden político, sin embargo los gobiernos que lo auspiciaron son ideológicamente opuestos: un régimen revolucionario de carácter marxista en Cuba y una dictadura militar conservadora en Argentina.

\section{La actualización cinematográfica de los relatos fundacionales argentinos}

Revista Eletrônica da ANPHLAC, n.14, p. 241-264, jan./jun. 2013. http://revista.anphlac.org.br/index.php/revista 
A partir del golpe de Estado del 25 de junio de 1966, bajo la dictadura de Juan Carlos Onganía y los regímenes de facto de Roberto M. Levingston y Alejandro A. Lanusse, se agravaron en Argentina las limitaciones de la libertad de expresión, principalmente tras el Decreto Ley 18019 de 1968 (OUBIÑA, 2004, p 76, 77). Ante esta situación los cineastas se interesaron por temáticas evasivas que evitaban abordar la contingencia nacional, como la comedia popular, el musical y el drama histórico. El auge de este último puede entenderse, por lo tanto, como una forma de eludir la contingencia de parte de los realizadores que se mantenían dentro de los cauces permitidos al cine por el régimen; sin embargo, es también una producción cinematográfica afín al discurso nacionalista de la dictadura.

Alentado por desde el gobierno y con el apoyo financiero del Instituto Nacional de Cinematografía se produjeron durante la dictadura un número importante de filmes centrados en los héroes de la patria y en figuras arquetípicas del folclor, como el gaucho argentino. Junto con homenajear ciertos arquetipos de la "argentinidad" y figuras históricas de relevancia, estos filmes exaltan el honor militar de los héroes, su abnegación, amor a la patria y dotes de mando castrense, en un discurso acorde con los intereses de la dictadura (ERAUSQUIN, 2008, 115).

Se destacan dentro de este ciclo histórico-folklórico -también conocido como criollista-histórico (LUSNICH, 2005, p. 410)- tres films de Leopoldo Torre Nilsson: Martín Fierro (1968), El Santo de la espada (sobre José de San Martín'1, 1970), Güemes, la tierra en armas (sobre Miguel de Güemes ${ }^{2}$, 1971); dos de Manuel Antín, Don Segundo Sombra (1969), Juan Manuel de Rosas ${ }^{3}$ (Antín, 1972) y el filme de René

\footnotetext{
1 José Francisco de San Martín (1778-1850) uno de los principales líderes militares de las Guerras de Independencia de Argentina, Chile y Perú. Dirigió el Regimiento de Granaderos a Caballo, que detuvo las incursiones realistas en el río Paraná (1813), posteriormente el Ejército del Norte, encargado de frenar a las tropas realistas en la provincia de Salta (1814). Ese mismo año fue nombrado Gobernador de Cuyo (Mendoza) donde organizó el Ejército de los Andes, formado por tropas argentinas y refugiados chilenos. Con ese ejército derrotó a los realistas en Chile (en las batallas de Chacabuco, 1817, y Maipú, 1818). Desde Chile encabezó una expedición marítima hacia el Virreinato del Perú. Consiguió ocupar Lima en 1821, declaró la independencia y fue nombrado Protector del Perú. En 1822 se reunió con Simón Bolívar en Guayaquil, después del encuentro decidió volver a las Provincias Unidas del Río de la Plata, dejando a Bolívar continuar las campañas contra los realistas. Vivió exiliado en Francia entre 1824 y 1850.

2 Martín Miguel de Güemes (1785-1821) líder militar argentino, uno de los principales artífices de la llamada "Guerra Gaucha", que consiguió contener a los ejércitos realistas en la provincia de Salta. Dirigió acciones contra los realistas en Potosí al inicio de la Guerra de Independencia y formó parte del Ejército del Norte, principalmente bajo el mando de San Martín y Rondeau (con éste último tuvo profundos conflictos, que lo llevaron a dejar la expedición en Alto Perú). Fue nombrado Gobernador de Salta en 1815 y, desde allí, utilizando métodos de la guerra de guerrillas, logró frenar a los ejércitos realistas enviados desde Alto Perú para intentar retomar el control de la Provincias Unidas del Río de la Plata.

3 Juan Manuel de Rosas (1793-1877) militar y político argentino. Fue uno de los líderes del bando federalista en la guerra civil contra los unitarios de Lavalle. Tras la victoria de los primeros, fue elegido Gobernador de la Provincia de Buenos Aires (1829). Durante su mandato se produjo un conflicto armado
}

Revista Eletrônica da ANPHLAC, n.14, p. 241-264, jan./jun. 2013. http://revista.anphlac.org.br/index.php/revista 
Mugica Bajo el signo de la patria (sobre Manuel Belgrano ${ }^{4}$, 1971). Estos largometrajes suponen un quiebre profundo en la obra de sus autores, que habían formado parte de la renovación formal y temática de principios de la década anterior. Por un lado se trata de producciones que cuentan con un presupuesto ampliamente superior al de sus anteriores películas; por otro, en ellas abandonan el drama psicológico, la preocupación por las problemáticas de la juventud y la clase media y el tono intimista que los había caracterizado en los años sesenta.

La elección de temáticas que exaltaban las grandes gestas nacionales, siguiendo las versiones hegemónicas y tradicionales de la historia, facilitó que estos filmes conquistaran los favores del público. Este hecho se ve potenciado también por la contratación para los roles protagónicos de dos de las principales estrellas argentinas de la época, Alfredo Alcón en la trilogía de Torre Nilsson e Ignacio Quirós en el filme de Mugica. En el caso de El santo de la espada la taquilla superó las expectativas más optimistas, la película se convirtió, en ese entonces, en la más vista de la historia del cine argentino y su éxito alentó la realización de otras producciones de corte histórico.

Estas películas privilegian una interpretación del pasado que, como señala Philippe Raxhon, es heredera de la historiografía positivista (2002, p. 156) y de la semblanza de los héroes llevada a cabo por Mitre. Se trata de un cine donde los procesos históricos se explican por las acciones emprendidas por grandes héroes, que representan los valores de la argentinidad antes incluso de que el proyecto nacional haya cristalizado. El sesgo positivista y el contexto dictatorial en que vivía Argentina, hizo que en estos filmes se pusiera el acento en la narración de batallas y campañas militares, en detrimento del estudio de las mentalidades. Prisionero de la censura este cine ofreció una visión oficial del pasado, que fosilizaba los procesos históricos o los relatos

entre el Pacto Federal (Buenos Aires, Santa Fe y Entre Ríos) y las provincias del interior, agrupadas bajo la Liga Unitaria, con victoria de los federalistas. En 1833 y 1834, después de dejar el gobierno de Buenos Aires, dirigió una campaña contra los indígenas para ampliar y asegurar las fronteras de la provincia. Fue elegido nuevamente gobernador en 1835 y se convirtió en el principal líder de la Confederación Argentina (1835-1852). Su segundo mandato se caracterizó por políticas autoritarias y represión de opositores, por favorecer a los grandes ganaderos y por el enriquecimiento de Buenos Aires mediante impuestos aduaneros. Durante este período el puerto de Buenos Aires sufrió bloqueos franceses y anglofranceses. Rosas fue vencido en 1852 por un ejército al mando de Urquiza, gobernador de Entre Ríos, y se exilió en Inglaterra, donde residió hasta su muerte.

4 Manuel Belgrano (1770-1820) militar y político argentino. Miembro de la Primera Junta de Gobierno, combatió a los realistas en el actual Paraguay y en Montevideo. En 1812 creó la bandera argentina. Ese mismo año se le encomendó la dirección del Ejército del Norte y obtuvo importantes victorias en Tucumán (1812) y Salta (1813). Dirigió la Segunda Campaña en el Alto Perú contra los realistas, pero fue vencido y tuvo que replegarse en Juyjuy. Posteriormente viajó a Europa junto a Rivadavia, con el objetivo de que algún príncipe europeo se coronase monarca constitucional de las Provincias Unidas. Ante el fracaso de las negociaciones propuso, sin éxito, que la corona fuera atribuida a algún príncipe inca.

Revista Eletrônica da ANPHLAC, n.14, p. 241-264, jan./jun. 2013. http://revista.anphlac.org.br/index.php/revista 
folklóricos al evitar establecer nexos entre los conflictos del pasado y la inestabilidad social de la Argentina de los años setenta.

A pesar de ello, la exaltación del estoicismo y patriotismo de los próceres nacionales o de personajes tutelares como Martín Fierro era cercana al discurso político de la dictadura. Torre Nilsson y Ulyses Petit de Murat escribieron la historia de El Santo de la espada a partir del relato homónimo de Ricardo Rojas (1933), pero siguiendo fuentes tradicionales como Pacífico Otero ${ }^{5}$, Busaniche ${ }^{6}$ y Mitre ${ }^{7}$. En 1971 el director afirmó haber querido representar al héroe según la tradición: "Ese San Martín solemne y broncíneo, el que nos enseñaron en la escuela es el único que conozco. No soy revisionista” (MARANGHELLO y PALADINO, 2010, p. 37).

En el filme se liman diversas "asperezas" históricas de San Martín. El cineasta presenta al héroe profundamente enamorado de su bella esposa Remedios (la popular Evangelina Salazar) lo cual, como advierte Estela Erausquin (2008, p. 145), tiene más de licencia, de recurso de película de capa y espada, que de rigor histórico. Con todo, las alusiones indirectas a su vida íntima del héroe nacional son completamente omitidas. Cabe señalarse que el propio general Onganía exigió ver el filme antes de su estreno y le impuso a Torre Nilsson el corte de algunas escenas, en las que se le mostraba padeciendo dolores estomacales o excesivamente cariñoso con su mujer.

En la trilogía de Torre Nilsson, en los filmes de Antín y en el de Mugica se hace hincapié en los distintos acentos regionales, como una forma de realzar a través de un cierto pintoresquismo, las tradiciones nacionales. Esta caracterización roza la caricatura en el caso de Güemes y de los personajes que vienen de Salta, Jujuy o Tucumán. San Martín, por el contrario, al desembarcar en Buenos Aires, con 34 años, y a pesar de haber vivido 27 en España, tiene un acento argentino neutro. Si para los fines de la película resultaba totalmente inconcebible mostrar al padre de la patria padeciendo una

\footnotetext{
5 José Pacífico Otero (1874-1937), historiador argentino, doctor en filosofía, derecho civil y derecho canónico, fundó el Instituto Sanmartiniano en 1933. Entre sus principales obras se encuentra una historia de San Martín en cuatro tomos: Historia del Libertador don José de San Martín (1932).

6 José Luis Busaniche (1892-1959), historiador argentino, fue profesor del Instituto Nacional del Profesorado de Paraná y, posteriormente, de la Universidad de Buenos Aires. Entre sus principales obras sobre el proceso de emancipación argentina se encuentran San Martín visto por sus contemporáneos (1942), San Martín vivo (1950) y Rosas visto por sus contemporáneos (1955).

7 Bartolomé Mitre (1821-1906) militar, político e historiador argentino. Fue presidente de Argentina entre 1862 y 1868 y fundador del diario La Nación. Su obra como historiador contribuyó ampliamente a crear una visión oficial del pasado argentino, que gozó de una posición hegemónica en la segunda mitad del siglo XIX y buena parte del XX. Entre sus libros se destacan: Historia de Belgrano y de la Independencia Argentina (1856, versión definitiva de 1887), e Historia de San Martín y de la Emancipación Sudamericana (en tres volúmenes, 1887, 1888 y 1890).
}

Revista Eletrônica da ANPHLAC, n.14, p. 241-264, jan./jun. 2013. http://revista.anphlac.org.br/index.php/revista 
gastritis, mucho más lo era escucharle hablando como un perfecto andaluz, por más que numerosos documentos de la época atestigüen que ese era su registro.

La representación de San Martín es la de un mito: viste siempre de uniforme, tiene una claridad total respecto de sus objetivos y la manera de lograrlos y es prácticamente inexpresivo, Alcón encarna a un héroe que parece de bronce como las estatuas en las que se inspira. Consecuentemente con ello la cámara toma cierta distancia con él, suele ser filmado en plano general, americano o medio, pero escasamente en primer plano o primerísimo primer plano -un acercamiento que permite poner de relieve las emociones. El título del film sacraliza (o santifica) al personaje histórico, haciendo un juego de palabras con su apellido y sin tener muy en cuenta su poca simpatía - por no hablar de animadversión- respecto de la Iglesia Católica. La película sólo aborda un periodo restringido de su biografía (1812 - 1823), es decir desde su llegada a Argentina hasta los meses previos a su exilio en Europa. Por otro lado, como en el caso del Belgrano de Mugica las razones de su participación en la guerra son abordadas sucintamente o presupuestas: el amor a la patria y la lucha contra la opresión española. San Martín parece decidido, desde un comienzo -desde que desembarca en el país y se presenta ante el Triunvirato- a luchar contra los españoles teniendo como objetivo la independencia argentina y latinoamericana, lo que es históricamente inexacto.

En el film no se menciona que fuera masón, no se dice que al igual que él sus hermanos eran militares del ejército español, tampoco se establece cuál fue su posición en las luchas de poder de las Provincias Unidas. El héroe parece decidido a liberar su país, Chile y Perú, sin hacer "política" e incluso deja entrever cierto desprecio por quienes se pliegan a los conflictos políticos del momento. "De muy poco entiendo, pero de política menos que nada", afirma, en lo que parece un discurso cercano a las justificaciones que enarbolaron las dictaduras latinoamericanas preocupadas de "salvar" a sus países de diversos "cánceres", sin hacer "politiquería".

San Martín y Belgrano, en los dos principales filmes del periodo, son representados como líderes natos, buenos estrategas y militares determinados que no ambicionan el poder, pero sí la defensa de la patria en peligro. La representación del líder militar -y del ejército- como el llamado a fundar la patria y defenderla frente al enemigo, se opone a la ineficacia y corrupción de los "políticos de Buenos Aires". En ambos filmes los héroes terminarán por entrar en conflicto o desobedecer a los políticos 
en pro de la nación, lo que aplicado al contexto de la época en que se produjo el filme parece legitimar a la Revolución Argentina.

Las referencias a la religión son bastante frecuentes en la película particularmente mediante objetos destacados, como crucifijos, o en escenas completas, como la boda con Remedios y las del convento de San Lorenzo (MARANGHELLO y PALADINO, 2010, p. 35). Las alusiones al catolicismo son bastante más explicitas en Bajo el signo de la patria. La profunda religiosidad de Belgrano -un rasgo marcado del personaje histórico- que el filme pone de relieve, puede entenderse como un correlato de la promoción de los valores y la moral católica de la dictadura. En distintas secuencias del filme, Belgrano, creador de la bandera argentina, se defiende vehementemente de acusaciones de herejía, hace bendecir el pabellón patrio, arrodillado en una capilla reza en voz alta por la nación, y llora a los pies de una estatua de la virgen, en una procesión, tras vencer al ejercito realista. El amor por la patria de Belgrano se representado como intrínsecamente unido a su declarado fervor religioso. Es posible ver en ello una referencia directa al proyecto social de Onganía, quien el 30 de noviembre de 1969 consagró la República Argentina al Inmaculado Corazón de la Virgen María.

Pese al discurso nacionalista del cine histórico-folklórico, no se advierte en estos filmes ningún tipo de antiespañolismo. Los realistas son los enemigos, pero ni su ejército ni sus líderes son retratados como particularmente crueles. Pío Tristán el mayor antagonista de Belgrano en el filme de Mugica deja en claro en su primer diálogo que al igual que los sublevados él es un criollo y no un peninsular. Más tarde evocará su antigua cercanía con el líder independentista en sus años de estudiante en Salamanca. Los fusilamientos y las torturas a las que someten los realistas a sus prisioneros no son distintas de las que llevan a cabo el ejercito del norte, aunque eso sí en el filme se deja en claro que Belgrano no le agradan esas prácticas y las ve como un último recurso a utilizar. Por último, los móviles que guían al ejercito realista tampoco están excesivamente desarrollados, sólo se evocan en forma sencilla: lealtad al rey.

La ausencia de animosidad contra España, puede deberse a que la dictadura fomentó las relaciones con el régimen de Franco, con el que era cercano ideológicamente. En ambos casos se trata de un nacionalismo conservador que se había autodenominado como defensor de su pueblo frente al "comunismo" -el término debe entenderse en forma más amplia a lo que tradicionalmente designa- y pretendía refundar la nación sobre la base de ideales católicos.

Revista Eletrônica da ANPHLAC, n.14, p. 241-264, jan./jun. 2013. http://revista.anphlac.org.br/index.php/revista 
Por el contrario, las comunidades y los grupos étnicos excluidos del proyecto nacional -la población negra y los pueblos originarios- son retratados por el cine histórico-folklórico de manera mucho más crítica a la de los españoles. La negación de un espacio reservado para ellos, comienza por una política de exclusión racial en el reparto. Para encarnar a los personajes que provienen de estos grupos marginados, se elige, salvo algunas excepciones, a actores blancos y mestizos. Quizás el ejemplo más claro de ello sea el de la mulata al servicio de la esposa de Remedios en El santo de la espada que es interpretada, de manera caricaturesca por una actriz blanca, Ana María Picchio. Se trata de una estrategia que había sido largamente empleada por el cine clásico de Hollywood que, como explican Robert Stam y Ella Shohat, impide la autorrepresentación de dichos grupos (2002, p. 196).

De la misma manera, los indios pampa de Martín Fierro son retratados como salvajes despiadados que se dedican al pillaje con extrema crueldad. Ciertamente, la película reproduce algunos pasajes del poema original de Hernández, pero no por ello deja de llamar la atención que cien años después Torre Nilsson no haya permitido ciertas licencias respecto de la fuente original -como en el caso de El santo de la espada- ni desarrolle una perspectiva crítica o un cierto distanciamiento respecto de estos episodios. Resulta decidor que el único pampa "bueno" del filme sea precisamente el que termina por manifestar su deseo de convertirse al cristianismo. El filme, se hace eco, así, de la dicotomía decimonónica de "civilización o barbarie", expresada en el Facundo de Sarmiento, y que había servido como sustento ideológico de las campañas de ocupación de la pampa argentina y de las políticas de atracción de inmigrantes europeos.

Si en estos filmes el enemigo de la libertad criolla es el bando realista, el enemigo de la civilización cristiana, es el indígena. Emanciparse de España no significa, bajo ningún concepto, desligarse de la filiación cultural con el occidente europeo. La ausencia de una mayor animadversión hacia España permite construir una filiación entre criollos y españoles, que sitúa el germen de la nación, eminentemente, en sus raíces europeas y católicas. La injerencia cultural de otros colectivos en esos procesos es negada, sea mediante su ridiculización (el rostro embadurnado de la mulata Picchio) sea mediante la atribución de conductas inhumanas (los indios pampas). El origen de la patria, el nacimiento de la argentinidad, se sitúa, así, tanto en lucha por la libertad nacional como en el combate por la civilización.

Revista Eletrônica da ANPHLAC, n.14, p. 241-264, jan./jun. 2013. http://revista.anphlac.org.br/index.php/revista 


\section{Actualización y contra-historia}

Una estrategia de representación diametralmente opuesta asumirá el Grupo Cine Liberación (GCL) integrado por Fernando Solanas, Octavio Getino y Gerardo Vallejo. Su producción fílmica, que durante las dictaduras de Onganía, Levingston y Lanusse se desarrolló en forma clandestina o semiclandestina, se caracterizó por un revisionismo histórico que asoció el mito sanmartiniano con el peronismo y las luchas de liberación del Movimiento Tricontinental. Su discurso, influenciado por Frantz Fanon, Jean-Paul Sartre, Mao Zedong, Raúl Scalabrini Ortiz y Ernesto Guevara, encontró su mayor punto de eclosión en La hora de los hornos (1968) y el manifiesto Hacia un Tercer Cine (1969).

Los integrantes de GCL eran cercanos al peronismo revolucionario, una reinterpretación de izquierdas del discurso nacionalista elaborado por Juan Domingo Perón durante sus dos primeros mandatos. En los años sesenta, jóvenes intelectuales y antiguos dirigentes peronistas como John William Cooke ${ }^{8}$ habían establecido paralelos entre el peronismo y la Revolución Cubana que permitían, reactualizar las doctrinas y las medidas políticas de Perón, a partir de los ideales revolucionarios de las luchas de "liberación" (independencia política y económica y descolonización cultural) de los países del llamado Tercer Mundo. Como establece Silvia Sigal esta "reconstrucción retrospectiva" del peronismo (1996, p. 222) permite atribuirle el carácter de un socialismo nacional, que el movimiento justicialista no tuvo en su origen. El peronismo revolucionario, de esta manera, resulta del cruce del nacionalismo populista y antiimperialista de Perón con las teorías marxistas, guevaristas y castristas. Junto con la promoción de acciones armadas rurales y urbanas de corte guevarista, la defensa y promoción de esta reinterpretación ecléctica del peronismo es el principal objetivo de La hora de los hornos.

El acercamiento a las reinterpretaciones revolucionarias permitió conectar con el sentir de una nueva generación de argentinos proclive a la idea de la «liberación » y sirvió de aliento para organizaciones armadas peronistas, como Montoneros, que intentaron propiciar el retorno del general asestando golpes armados contra la dictadura de Levingston y Lanusse 9 . Desde Madrid el mismo Perón pareció legitimar esta reinterpretación de sus doctrinas, haciendo un llamado a una « liberación del Tercer

\footnotetext{
8 Cooke intentó convencer a Perón de exiliarse en Cuba tras el triunfo de la revolución. El general continuó, sin embargo, viviendo en la España franquista.

9 Entre sus acciones armadas la más importante fue el secuestro y asesinato del general Pedro Eugenio Aramburu dictador argentino entre 1955 y 1958.
}

Revista Eletrônica da ANPHLAC, n.14, p. 241-264, jan./jun. 2013.

http://revista.anphlac.org.br/index.php/revista 
Mundo » en su libro La hora de los pueblos ${ }^{10}$ (1968). Sin embargo, en la práctica no hubo un viraje real hacia políticas de izquierda, de parte del general. A pesar de las señales dadas por Perón en favor de la "izquierda peronista revolucionaria", esta reinterpretación del peronismo no logró alcanzar una posición mayoritaria al interior del movimiento, que también era apoyado por tendencias de derecha. En la práctica Perón se rodeó de un círculo de asesores que pertenecían al ala conservadora del justicialismo.

Junto con el "peronismo revolucionario", otro de los aspectos que caracteriza los planteamientos teóricos de GCL es la negación del valor universal de los modelos estéticos eurocéntricos. Los valores estéticos y culturales occidentales fueron rechazados por el grupo o vistos como una imposición "imperialista", llevada a cabo con la colaboración de las burguesías nacionales néocolonizadas y que acarreaba interacciones problemáticas con los imaginarios colectivos y el acervo cultural autóctono. La crítica a la tradición cultural que promovía la burguesía, implicó a su vez un rechazo de las interpretaciones de la historia y la cultura argentinas que habían sido realizadas recurrentemente por las oligarquías nacionales desde el siglo XIX. Estas interpretaciones -de las que se hace eco el cine histórico-folklórico oficial- celebraban la lucha por la implantación de modelos occidentales como un elemento clave en el desarrollo de la identidad nacional.

Por el contrario, el posicionamiento que adoptó grupo Cine Liberación, emparenta sus films con el "revisionismo histórico" emprendido desde los años treinta por intelectuales como Raúl Scalabrini Ortiz, que había llevado a cabo una revisión crítica de la historia argentina -verdadera "contra-historia"-, para desenmascarar las interpretaciones dominantes de la historia y fundar otras nuevas, que cumplirían una importante función simbólica: la producción o reconstrucción de un pasado que legitimaba los discursos nacionalistas y los proyectos de descolonización cultural (SIGAL, 1996, p. 233).

Por ello, si el sesgo positivista había marcado el cine histórico argentino de fines de los años sesenta y principios de los setenta; puede decirse que los filmes de GCL se caracterizará, por su parte, por una actitud de constante sospecha frente a la historiografía oficial, que conduce a un ejercicio cinematográfico de contra-historia. El grupo hace explicito, este posicionamiento, al principio de La hora de los hornos, a

10 El libro fue publicado en agosto de 1968, dos meses después del estreno en Pesaro de La hora de los hornos. El parecido entre los títulos de ambas obras podría no ser una coincidencia, pues La hora de los hornos adhería a los postulados del "peronismo revolucionario" y había suscitado una enorme polémica pública en Argentina, a raíz de su carácter abiertamente contrario a la dictadura de Onganía.

Revista Eletrônica da ANPHLAC, n.14, p. 241-264, jan./jun. 2013. http://revista.anphlac.org.br/index.php/revista 
través de una cita de Scalabrini Ortiz: "Es falsa la historia que nos enseñaron, falsas las riquezas que nos aseguran, falsas las perspectivas mundiales que nos presentan (...)".

El filme sitúa en el proceso de emancipación del siglo XIX, el origen de la dependencia política y económica de América Latina frente a las potencias occidentales. Dicho proceso histórico es reinterpretado desde un punto de vista opuesto a la versión canónica:

La independencia de los pueblos latinoamericanos -afirma el narrador- fue traicionada en sus orígenes. La traición corrió por cuenta de las élites exportadoras de las ciudades puerto. El mismo año que Bolívar consolidaba la Independencia en Ayacucho, Rivadavia firmaba en Buenos Aires el empréstito estafa de la banca Baring Brothers.

La actitud de sospecha va de la mano con un llamado a redescubrir o reinterpretar el discurso de la Independencia desde la óptica de la lucha antiimperialista. Al comienzo de Acto para la liberación, la segunda parte de La hora de los hornos, se nos indica que estamos ante "notas, testimonios y debate sobre las recientes luchas de liberación del pueblo argentino". Sin embargo, poco después, aparece en pantalla un documento que pertenece a un momento histórico muy anterior, se trata de la Orden General dictada por José de San Martín el 27 de julio de 1819:

Compañeros del exercito de los Andes: La guerra se la tenemos que hacer del modo que podamos: si no tenemos dinero, carne y un pedazo de tabaco no nos tiene que faltar: cuando se acaben los vestuarios, nos vestiremos con la bayetita que nos trajeron nuestras mujeres, y si no andaremos en pelota como nuestros paisanos los indios: seamos libres, y lo demás no importa nada... Compañeros, juremos no dejar las armas de la mano, hasta ver el país enteramente libre, ó morir con ellas como hombres de corage ${ }^{11}$.

Estas palabras son acompañadas por imágenes de alzamientos populares de los años cincuenta y sesenta y llamados a la acción violenta, mediante distintos intertítulos. El prócer argentino es, de esta forma, rescatado de los bronces para volverse un líder revolucionario, plenamente contingente. Poco importa a Solanas y Getino que el San Martín histórico propusiera que los pueblos americanos fueran gobernados por príncipes europeos y afirmara estar "convencido de la imposibilidad de erigir estos países en república" (ACEVEDO, 1992, p. 191), lo que evidentemente lo aleja del discurso

\footnotetext{
11 Se ha respetado la ortografía del texto original, tal como es citado en La hora de los hornos, las cursivas son nuestras. En el mismo periodo en que el filme circuló clandestinamente en Argentina, este texto era distribuido en forma de panfletos por las Fuerzas Armadas Revolucionarias (Erausquín, 2008, p. 113) lo que muestra que la utilización de fuentes históricas por grupos más o menos cercanos al peronismo no se produjo sólo en el campo cinematográfico.
}

Revista Eletrônica da ANPHLAC, n.14, p. 241-264, jan./jun. 2013. http://revista.anphlac.org.br/index.php/revista 
revolucionario enarbolado por GCL. Al igual que en el caso de la dictadura, lo que se intenta es buscar la legitimación de un proyecto nacional apoyándose en figuras tutelares de Argentina. Sin embargo la estrategia seguida para ello es diferente. Los regímenes militares privilegiaron tropos y paralelismos entre sus acciones y los mitos históricos, en una actitud que podría resumirse así: nosotros somos como fue San Martín. Solanas y GCL, por el contrario, plantearon la idea de la actualización de la figura histórica: nuestra lucha y la de San Martín son la misma. Este último posicionamiento implica el abandono de una lectura cronológica del pasado. El proceso de emancipación ya no está anclado en la Historia, sino que forma parte de un continuum, de una lucha que debe ser actualizada por la colectividad que presencia la cinta. La hora de los hornos contempla la interrupción del filme para que se realicen debates a partir de lo que se acaba de ver, en un intento por convertir al espectador en actor político.

Los militantes peronistas fueron los principales destinatarios tanto de La hora... como de los dos filmes siguientes de GCL. Se trata de Actualización política y doctrinaria para la toma del poder y La revolución justicialista (1971-1972) dos entrevistas a Perón, realizadas en Madrid, que como La hora de los hornos fueron distribuidas en circuitos clandestinos. Después de realizar esos largometrajes el grupo cambió de estrategia de producción. En 1971 el proceso de democratización del país ganaba terreno y se aproximaba el retorno del peronismo al poder. En este contexto, GCL concibió filmes para los circuitos tradicionales de cine (TAL, 2005, p. 124). Vallejo filmó El Camino hacia la muerte del viejo Reales, y Getino, El familiar. Solanas, por su parte, en 1972 se embarcó en la tortuosa realización de Los hijos de Fierro.

Este último filme se inspira libremente en el poema Martin Fierro de José Hernández (1872), que denuncia el abuso cometido por el Estado argentino contra los gauchos que eran reclutados por la fuerza para combatir contra los pueblos originarios, a fines del siglo XIX, en las pampas. El poema cuenta la historia de uno de ellos, Martín Fierro, que simboliza la libertad, la resistencia y entereza que la tradición romántica ha atribuido a los gauchos. Solanas hace una reinterpretación del poema en el centenario de su escritura en la que trata de asociar al justicialismo uno de los mitos fundacionales de la nación argentina. Su objetivo es actualizar la obra, construir a partir de ella una alegoría de las luchas del movimiento peronista tras la caída de Perón, en 1955. El proletariado argentino se convierte en el filme en depositario de los valores de Fierro.

Revista Eletrônica da ANPHLAC, n.14, p. 241-264, jan./jun. 2013. http://revista.anphlac.org.br/index.php/revista 
El filme es en parte una respuesta a la adaptación, fuertemente historicista, de Martín Fierro realizada por Torre Nilsson en 1968. Solanas había acusado a este último de no ver en Martín Fierro "el conflicto todavía vigente del pueblo argentino contra la oligarquía" (GETINO y SOLANAS, 1973, p. 95). La película de Torre Nilsson se ambientaba en la pampa y se ceñía escrupulosamente al texto original -la adaptación estuvo a cargo de cinco personas- que se erigió como un sustento extra cinematográfico. Por el contrario, para su filme Solanas compuso nuevos versos de métrica octosilábica, como el poema de Hernández. Estos versos entremezclados con fragmentos del original constituyen, en lo esencial, la voix over de Los hijos de Fierro. La búsqueda por actualizar el relato se tradujo en una concepción espacio-temporal de gran complejidad. La puesta en escena cuenta con pasajes ambientados en el siglo XIX, imágenes de archivo del Cordobazo (1969), entrevistas a agentes de la policía, recreación de torturas y de tomas de fábricas en un presente indeterminado y en un espacio eminentemente urbano.

La resistencia del pueblo representada a través de huelgas, manifestaciones, conflictos sindicales y acciones armadas adquiere la forma de un relato legendario. El héroe del filme son los tres hijos de Fierro -llamados el hijo mayor, Picardía, y el hijo menor- que simbolizan las diferentes tendencias del peronismo revolucionario. El primero encarna la lucha armada, el segundo los sindicalistas y el tercero las nuevas generaciones de trabajadores. El narrador explica que en cada barrio obrero hay un hijo mayor, uno menor y un Picardía, lo que permite deducir que los tres son representaciones de la colectividad. Su lucha tiene como objetivo el regreso de su padre -una paternidad comprendida en un sentido político y no biológico- que es presentado como una metáfora de Perón.

La actualización de Martín Fierro realizada por Solanas parece heredera de las consideraciones de Frantz Fanon sobre la cultura popular y la lucha por descolonización ${ }^{12}$. El psiquiatra martiniqueño otorga un espacio importante de su obraparticularmente en Los condenados de la tierra- a explicar que la reacción contra la

\footnotetext{
12 Es necesario recordar que para GCL Argentina y América Latina están inmersas en un sistema Neocolonial que se caracteriza por una alianza entre las metrópolis "imperialistas" y las élites autóctonas y que conlleva a la dependencia de estos países respecto de Europa occidental y Estados Unidos. El neocolonialismo se diferencia del colonialismo tradicional en que, por norma general, no hay ejércitos de ocupación -el monopolio de la fuerza es ejercido por los cuerpos de policía y los ejércitos nacionales- y, además, los países neocoloniales son teóricamente independientes en términos políticos. Sin embargo, la dependencia estructural entre ellos y la metrópoli continúa. Es por ello que GCL establece vínculos entre el sistema colonial y el neocolonialismo, lo que les permite adaptar el pensamiento de Fanon a América Latina, en general, y Argentina, en particular.
}

Revista Eletrônica da ANPHLAC, n.14, p. 241-264, jan./jun. 2013. http://revista.anphlac.org.br/index.php/revista 
imposición de los modelos culturales occidentales no puede limitarse al estudio y a la defensa de la tradición autóctona. La exaltación del pasado nacional es descrita por Fanon como un momento de ruptura, una segunda fase por la que atraviesan los intelectuales colonizados, después de un primer periodo durante el cual la intelectualidad ha tratado de demostrar que ha asimilado integralmente la cultura de la metrópoli. Este segundo periodo sirve para manifestar el rechazo a someterse al colonizador; pero conlleva el riesgo de llevar al artista y al intelectual al inmovilismo, a las formas inertes e inactuales que no se ajustan a los conflictos del presente y dificultan el "encuentro" entre el artista y el pueblo: "No basta con unirse al pueblo en ese pasado donde ya no se encuentra sino en ese movimiento oscilante que acaba de esbozar y a partir del cual, súbitamente, todo va a ser impugnado" (FANON, 1961, p. 215).

Por último, Fanon establece un tercer periodo en que el intelectual verá en la "liberación" un proceso en el que se manifiesta con todo su potencial la cultura nacional. La lucha por la liberación es concebida como una condición necesaria para el surgimiento de la cultura nacional. Ésta última se desarrolla en el presente, a partir de las necesidades de la lucha de liberación, su carácter por ello mismo es eminentemente subversivo. El intelectual busca, en palabras de Fanon, "sacudir al pueblo". "En vez de favorecer el letargo del pueblo se transforma en el que despierta al pueblo. Literatura de combate, literatura revolucionaria, literatura nacional". (FANON, 1961, p. 178).

Siguiendo el esquema de Fanon podría decirse que Solanas y el GCL desarrollan una obra cinematográfica que se inscribe en este tercer periodo. La adaptación de Martín Fierro no busca la exaltación de la tradición folklórica, ni mira hacia el pasado decimonónico. Por el contrario, huye de lo anterior -de ahí sus críticas a Torre Nilssonpara recontextualizar el texto, anclarlo en la contingencia, con el objetivo de testimoniar, acompañar y potenciar las luchas obreras del movimiento peronista. El título mismo del filme encierra la doble connotación de herencia y actualidad al hacer hincapié en los "hijos" de Fierro, vale decir, los depositarios de su legado y los encargados de continuar su lucha.

\section{La Independencia en el cine cubano}

La ley de fundación del Instituto Cubano de Arte e Industria Cinematográficos (ICAIC), publicada a escasos meses del triunfo de la revolución de 1959, establece que la historia cubana sería uno de los principales temas que abordaría el naciente cine revolucionario cubano. La finalidad de los films históricos está también delineada por la 
ley: ser una "fuente de inspiración revolucionaria, de cultura y de información". Como puede observarse, se trata de una concepción abiertamente didáctica, en la que confluye la enseñanza del pasado, con la difusión de la ideología del régimen revolucionario.

La mayoría de los primeros filmes de ficción del ICAIC están ambientados en el pasado inmediato de la isla, antes del triunfo de la revolución, y tienen como principales escenarios a La Habana durante la dictadura de Batista y los combates en la Sierra Maestra. Cabría citar, por ejemplo, Historias de la revolución (Tomás Gutiérrez Alea, 1960), Cuba Baila (Julio García-Espinosa, 1960), El joven rebelde (Julio GarcíaEspinosa, 1961), Cuba '58 (Jorge Fraga, José Miguel García Ascot, 1962), la coproducción soviético-cubana Soy Cuba (Mikhail Kalatozov, 1964), El robo (Jorge Fraga, 1965), Manuela (Humberto Solas, 1966) y Aventuras de Juan Quinquín (Julio García-Espinosa, 1967), entre otros.

El tema que abordan con mayor frecuencia estas obras es la lucha revolucionaria, representada como un hito fundacional. De la mano con ella, como un proceso prácticamente indisociable, en estos filmes se le da una importancia de primer orden a la toma de conciencia revolucionaria de los protagonistas. La revolución como hecho fundador, va de la mano, así, con el advenimiento de un "hombre nuevo", representado a través del héroe guerrillero. Por último, la descripción de la corrupción moral y del arribismo de la pequeña burguesía, durante la dictadura de Batista, es en menor medida, otra de las temáticas que se repiten.

Sólo a partir de 1968, cuando la lucha de la Sierra Maestra y el derrocamiento de Batista ya han sido profusamente tratados por el cine cubano, cobra una importancia de primer orden la representación de periodos históricos anteriores, particularmente la independencia. Tres de los siete largometrajes cubanos que se estrenaron en 1968 y 1969 abordaron el proceso de emancipación: Lucía (Humberto Solás, 1968), La odisea del general José (Jorge Fraga, 1968) y La primera carga al machete (Manuel Octavio Gómez, 1969). A ellos se suman documentales, cortometrajes y mediometrajes: Hombres de mal tiempo (Alejandro Saderman, 1968), El llamado de la hora de (Manuel Herrera, 1969), Médicos mambises (Santiago Villafuerte, 1969), etc.

El centenario de la Guerra Grande (1868 - 1878) es uno de los motivos que impulsaron este cine histórico. El ICAIC asoció en forma clara las guerras de independencia con la revolución de 1959, dentro de un ciclo cinematográfico conocido como los “100 años de lucha por la liberación”. Las causas de la preponderancia de este tipo de cine durante los años setenta habría que situarlas, sin embargo, no sólo en el 
hecho de que se cumpliera un siglo desde la primera guerra de independencia, sino que más bien en la compleja situación que atravesaba la isla en ese decenio. El incremento de películas históricas puede entenderse, en parte, como un repliegue hacia temáticas en torno a las cuales existía cierto consenso nacional y que, como en el caso de Argentina, eran fomentadas por el régimen con una intención legitimadora y didáctica.

A fines de los años sesenta, la burocratización, el dogmatismo, los primeros traspiés en política exterior y el posterior fracaso de la zafra de los diez millones acarrearon críticas crecientes $\mathrm{y}$, posteriormente, un paulatino desinterés hacia a la Revolución Cubana de parte la intelectualidad de izquierdas europea. En términos generales, las simpatías hacia Cuba y el entusiasmo declarado que había suscitado la revolución en los albores de los años sesenta -que se habían traducido en numerosos viajes a la isla- habían cedido terreno, en Europa, en beneficio de otras experiencias latinoamericanas, principalmente el Gobierno de Salvador Allende (1970 - 1973). A ello se suma una progresiva disconformidad de parte de la intelectualidad cubana, conocidos como "liberales", opuesto a sectores conservadores llamados "dogmáticos". Las rencillas ideológicas entre ambos, se saldaron a principios de los años setenta con un reforzamiento de estos últimos. Las campañas contra las modas extranjeras, los jeans, el pelo largo o la música de The Beatles, van de la mano con una censura creciente y con la represión de disidentes, persecución de homosexuales y de artistas acusados de "inconsistencia revolucionaria" o de "actividades subversivas", siendo el caso de Herberto Padilla el más emblemático, pero no el único.

La situación se agrava con el Primer Congreso de Educación y Cultura, en 1971, que supuso la purga de varios intelectuales y artistas, especialmente en las áreas de la literatura y el teatro, como indica Ambrosio Fornet, que ha llamado a este periodo el Quinquenio gris (1971 - 1976) (1990, p. 91) ${ }^{13}$. Según Díaz y Del Río: “El congreso había sido la culminación de la Ofensiva Revolucionaria, un proceso creciente desde finales de los años 60 y que disponía la incondicionalidad absoluta a la rectoría del partido en todas las ramas de la cultura [...]" (2010, p. 37). Ya a principios de los años sesenta, particularmente en 1963, se habían desarrollado polémicas públicas entre el ICAIC y los sectores conservadores de la dirección del país o del Partido Unido de la Revolución Socialista de Cuba, que se habían conseguido sortear en general a favor del Instituto. Sin embargo, la situación se invertiría a partir de 1971. Durante el Congreso

13 Marta Díaz y Joel del Río, utilizan el calificativo «gris » para hablar de todo el decenio y no solamente del lustro 1971-1976. (2010, p. 37).

Revista Eletrônica da ANPHLAC, n.14, p. 241-264, jan./jun. 2013.

http://revista.anphlac.org.br/index.php/revista 
de Educación y Cultura, se volvió a criticar al ICAIC sobre todo por la exhibición de filmes "decadentes" y se hizo hincapié en el rol del cine como "instrumento de la educación ideológica".

El ICAIC y la Casa de las Américas consiguieron conservar su autonomía productiva, pero a precio de redoblar la cautela y moderar sus contenidos. El Instituto de cine se replegó sobre sí mismo, temeroso de intervenciones externas. Quizás el Quinquenio gris no se tradujo en una consonancia directa entre el ICAIC y las políticas culturales emanadas del Congreso de Cultura pero sí existió una cierta "prudencia", de parte de los cineastas. En este contexto se produjo el referido incremento de filmes que ensalzan las luchas revolucionarias y de ficciones y documentales de temática histórica. Como en el caso del cine argentino comercial de fines de los años sesenta y principios de los setenta, la estrategia adoptada frente a un contexto de represión creciente fue la explotación del cine histórico. Con todo, no sólo se trató de una manera de evitar la contingencia, sino que también fue una respuesta a la petición formulada en el congreso de "eslabonar el presente con el pasado y plantear diferentes formas de divulgación y educación cinematográficas” (SÁNCHEZ GONZÁLEZ, 2010, p. 224).

En el cine cubano, las guerras de independencia son reinterpretadas a partir del discurso promovido por el régimen revolucionario, que se auto designaba heredero del proceso de emancipación. Este ciclo de "100 años de lucha por la liberación” tenía la clara voluntad de interpretar el pasado a partir de los conflictos del presente, de tal manera que las tres guerras de independencia, la lucha contra Machado y Batista y, posteriormente, las disputas con Estados Unidos fueron vistas, como explica Santiago Juan-Navarro "como partes de diferentes etapas dentro de una larga guerra de liberación nacional" (2006, p. 108). El Estado Socialista, sin embargo, no era solamente un escalón más dentro de la lucha contra el imperialismo español o estadounidense si no que se erigía como su etapa final, es decir, como su "conclusión histórica inevitable" (GARCÍA BORRERO, 2008, p. 133).

En 1971, el número 68 de la revista Cine cubano, publicada por el ICAIC, dedicó seis artículos al ciclo de los "100 años de lucha". El especial se abría con un texto de José Martí y continuaba con otro de Fidel Castro con un título altamente ilustrativo: "Fidel en los 100 Años de Lucha". La principal figura de la independencia y el primer ministro de Cuba quedaban así ligados, en las páginas de la principal revista de cine de la isla, como una suerte de origen y conclusión de un mismo proceso liberador. La asociación entre Castro y Martí que opera el cine cubano es aún más 
evidente en un documental realizado a fines del periodo que nos ocupa, Mi hermano Fidel (Santiago Álvarez, 1977). En el filme Salustiano Leiva, un anciano casi ciego que a los once años conoció a José Martí, es visitado por Fidel Castro. Leiva que no reconoce la voz de Castro le cuenta algunos antecedentes sobre el paso de Martí por la cala de Playitas, al inicio de la guerra de independencia. Sólo al final del documental, Fidel Castro, en un gesto que tiene algo de novelesco, revela su identidad, ante un Leiva al borde de las lágrimas. Martí y Castro quedan así enlazados a través del anciano, que se convierte en un testigo privilegiado de la Historia cubana. Tras su encuentro con Castro, el anciano recibe ayuda para recuperar la vista, en una escena de fuerte contenido simbólico. Para el discurso del film la llegada de Castro al poder sirve para cerrar un ciclo histórico iniciado por Martí y, a la vez, hace que se abra una nueva esperanza para la isla, de ahí que el campesino al entrar en contacto con Castro termine por recuperar la visión.

Las analogías entre los héroes del pasado y las figuras del presente, no se limitan a Martí y Castro. Ejemplo de ello es el paralelo entre Antonio Maceo ${ }^{14}$ y el Che en el documental El llamado de la hora de Manuel Herrera que hemos mencionado con anterioridad (GARCÍA BORRERO, 2008, p. 261). Sin embargo, el cine cubano no se limita a la asociación entre figuras emblemáticas del pasado y del presente. A pesar de la importancia otorgada a figuras individuales como Martí -por ejemplo en el filme Páginas del diario de José Martí, realizado por José Massip en 1971- el ICAIC le otorga mucha más importancia a producir filmes donde se establecer analogías entre procesos históricos o hitos relevantes para la isla que se dan de mediados del siglo XIX a mediados del siglo XX.

Las distintas etapas que marcaron el siglo que transcurre entre la Guerra Grande y la Revolución Cubana son mostradas de forma marcadamente teleológica como si cada una de ellas fuera un peldaño hacia la liberación revolucionaria. Quizás el caso más patente sea Lucía. Solás presenta a través de tres mujeres -llamadas Lucía- tres

\footnotetext{
14 Antonio Maceo (1845-1896) uno de los principales líderes militares de las Guerras de Independencia de Cuba. Después de la derrota de los independentistas en la Guerra de los Diez Años, rechazó el Pacto del Zanjón -acuerdo con el que se daba por finalizada la contienda. En una conferencia en Baraguá con el general español, Arsenio Martínez-Campos, Maceo anunció que no aceptaba el tratado de paz y que reanudaría las hostilidades. Desde el extranjero planeó, junto a Calixto García, la fallida invasión a Cuba que se conocería como Guerra Chiquita (1879). Se exilió en Jamaica, Honduras, Panamá y Costa Rica y entró en contacto con otros líderes independentistas, entre ellos, José Martí y Máximo Gómez, con los que organizó nuevas acciones armadas. En 1895 desembarcó en el sureste de Cuba (Baracoa). Después de controlar el Departamento de Oriente, avanzó hacia el occidente de la isla junto a Máximo Gómez, General en Jefe de las tropas independentistas. Murió en una acción militar a manos de las tropas españolas.
}

Revista Eletrônica da ANPHLAC, n.14, p. 241-264, jan./jun. 2013. http://revista.anphlac.org.br/index.php/revista 
momentos decisivos de la historia cubana reciente: la guerra de Independencia (1895), la lucha contra Machado (1932) y la etapa post-revolucionaria (el año no es precisado en el filme, sólo se menciona que ocurre en los sesenta). A diferencia de otros filmes del periodo, como La primera carga al machete, no se trata de un largometraje que aborde o se inspire siquiera en acontecimientos históricos precisos. En este sentido, las tres historias son completamente ficticias, pero su contexto es histórico (JOLIVET, 2006, p. 87). Los tres episodios unidos forman un fresco de 160 minutos que abarca unos setenta años de historia cubana. Cada historia es completamente independiente de las otras, sin embargo las une la lucha por la liberación, un motivo común coherente acorde con los presupuestos ideológicos de los "100 años de lucha".

Lucía, en sus tres vertientes, pasará de la sumisión amorosa a manos de un espía del ejército español, a la lucha por sus derechos en plena campaña de alfabetización, pasando por las acciones de lucha urbana contra Machado. El film puede ser interpretado como un retrato de la emancipación femenina, pero también como una metáfora de una sociedad que evoluciona de la alienación a la liberación. Como señala Paulo Antonio Paranaguá: "Las tres Lucía simbolizan entonces momentos claves de una trayectoria histórica inacabada, la búsqueda incesante de una emancipación” (1990, p. 143). Las tres historias dan cuenta de la progresiva toma de conciencia revolucionaria de la sociedad cubana.

Esta concientización liberadora comienza con un personaje que pertenece a la aristocracia (la primera Lucía) y que sólo descubrirá las consecuencias de sus actos muy tardíamente y en forma dramática; se extiende posteriormente a las clases medias (la Lucía de la segunda historia) y, gracias a la revolución y a las campañas de alfabetización, llega al campesinado (la tercera Lucía). La tercera Lucía anuncia así el advenimiento del hombre nuevo -aquí, la mujer nueva- que para el imaginario revolucionario debía surgir en y por la lucha por la revolución. Consecuentemente con ello el universo cinematográfico que construye Solás también varía de acuerdo a cada historia, lo que conduce a que el filme sea extremadamente diverso desde un punto de vista estético: va de un fuerte expresionismo audiovisual, de dimensión épica, fotografía sobreexpuesta y corte melodramático en el primer episodio, a una comedia violenta pero esperanzadora que denuncia el machismo del campo cubano, al ritmo de la canción Guajira Guantanamera.

El filme que aborda con mayor profundidad la Guerra Grande es La primera carga al machete (Manuel Octavio Gómez, 1969), que junto con Lucía constituye la 
obra más importante de este ciclo cinematográfico. El filme reconstruye, como su título indica, el combate del 4 de noviembre de 1968, al principio de la guerra, en el que las tropas coloniales españolas fueron vencidas por un grupo de cuarenta mambises armados de machetes. Aunque esta victoria no es la primera acción de la guerra, es representada por el filme como el mito fundacional de la independencia cubana, primera acción guerrilla desarrollada en la isla. Como apunta Juan-Navarro, la importancia acordada en el filme a este hecho y, en particular, al machete como símbolo de la liberación, puede asociarse a la relevancia que había adquirido este utensilio a fines de los años sesenta en Cuba, en plena zafra de los diez millones:

No podemos olvidar tampoco que cuando Manuel Octavio Gómez dirige su película (a finales de la década de los 60) se estaba sustituyendo la política inicial de rápida industrialización, diseñada para diversificar la economía, por la intensa producción de azúcar. En el momento en que se realizó La primera carga, el machete tenía por lo tanto una relevancia en el imaginario colectivo como no la había tenido antes, ni la habrá de tener después (JUAN-NAVARRO, 2006, p. 111).

Las analogías entre el pasado y el presente cubano no se reducen a este elemento. Para actualizar la guerra iniciada en 1868, en el filme se la reviste de un discurso asociado a la liberación nacional, a la Revolución y a la lucha contra la opresión, que genera consenso entre casi todos los personajes cubanos, pero que remite más al discurso hegemónico de la Cuba en la que se produjo el filme que a las razones históricas de la Guerra Grande.

El mayor elemento de actualización histórica no se encuentra en los diálogos de los personajes del filme, sino que en su puesta en escena. El filme es concebido como un docudrama en que la ficción se reviste de técnicas de cine directo: cámara al hombro, sonido directo, entrevistas, para recrear un conflicto desarrollado un siglo atrás. Manuel Octavio Gómez, micrófono en mano, recoge las impresiones de los personajes principales de ambos bandos, así como de soldados y población civil y se adentra por el lugar de las acciones bélicas o los centros de mando españoles y cubanos como lo haría un equipo del Noticiero ICAIC Latinoamericano. El resultado sirve para recrear una época histórica como si ya en ella hubiera existido el cine o cómo si los hechos estuvieran sucediendo en ese momento y no en el pasado. Esto le otorga al proceso histórico un sentido de la actualidad y de la urgencia similar a la que se plasmaba en el cine documental que abordaba conflictos armados de ese entonces y al que tenía acceso el público cubano (por ejemplo documentales sobre la guerra de Vietnam de Santiago 
Álvarez como Hanoi martes 13, 1967, y 79 primaveras, 1969). El acontecimiento histórico es, de esta forma, revestido de un aura de actualidad informativa porque, según el discurso del filme, la lucha que describe es completamente vigente, forma parte de la larga lucha por la liberación emprendida por el pueblo cubano.

Pese a los indudables méritos de filmes como Lucía y La primera carga al machete y de otros títulos como Una pelea cubana contra los demonios (Tomás Gutiérrez Alea, 1971) y La última cena (Tomás Gutiérrez Alea, 1976) el cine histórico cubano de los años sesenta y setenta supuso la postergación de una corriente cinematográfica más crítica con la contingencia. Aunque existía un interés por actualizar la lucha por la emancipación al contexto político cultural que vivía la isla, el proceso fue distinto al que había emprendido en esos años el GCL. Mientras que para el grupo argentino la actualización histórica era una manera de romper con el discurso oficial, es decir, de proponer una contrahistoria subversiva y acorde con el peronismo revolucionario, en el caso cubano el ICAIC enarboló, desde una posición dominante dentro del campo cinematográfico, un discurso propiciado por el estado.

A ello habría que añadir el riesgo de una sacralización y estandarización de los mitos nacionales, en Cuba, como la que llegó a producirse en el cine industrial de Argentina. En un contexto político y cultural en que las corrientes más conservadoras del régimen cubano lograban una posición dominante, los cineastas de la isla debieron aguzar su capacidad para jugar con el difuso margen de lo permitido, a fin de no terminar como el artista de La muerte de un burócrata (Gutiérrez Alea, 1966) que es engullido por la maquinaria en la que construye bustos en serie de José Martí.

Con todo, cabría señalar que para el cine histórico-folklórico argentino que mantuvo una posición hegemónica en el campo cinematográfico, el paralelo entre los mitos nacionales y el presente se restringe esencialmente a la exaltación de ciertas figuras tutelares de la historia y el folklor nacional -San Martín, Belgrano, Fierro- y sobre todo a la reivindicación de su conducta y de sus valores que se erigen como modelo de la argentinidad. Por su parte, el ICAIC se interesó más por establecer nexos entre el pasado y el presente, interpretándolos como un solo gran proceso liberador. El presente es interpretado así no sólo como una herencia del pasado, sino que se convierte ante todo en la finalidad hacia la que se encaminaban los procesos del pasado. Dicho de otro modo, el pasado adquiere solamente plena significación a la luz del presente, como si el principal objetivo de Máximo Gómez, de José Martí, de las figuras tutelares de la 
nación hubiese sido construir ese presente $-\mathrm{y}$ no otro- desde el cual los cineastas miraban al pasado.

\section{Referencias bibliográficas:}

ACEVEDO, Edberto Óscar. La independencia de Argentina. Madrid: MAPFRE, 1992.

BACZKO, Bronislaw. Les imaginaires sociaux, mémoires et espoirs collectifs. Paris: Payot, 1984.

DEL RÍO, Joel; DÍAZ, Marta. Los cien caminos del cine cubano. La Habana: Ediciones ICAIC, 2010.

ERAUSQUIN, Estela. Héroes de película: el mito de los héroes en el cine argentino. Buenos Aires: Biblos, 2008.

FANON, Frantz. Les damnés de la Terre. Paris : La Découverte \& Syros, [1961] 2002. FORNET, Ambrosio. Trente ans de cinéma dans la Révolution. PARANAGUÁ, Paulo. Antonio (dir). Le cinéma cubain. Paris: Centre Pompidou, 1990, pp. 79-105.

GARCÍA BORRERO, Juan Antonio. Cine Cubano de los sesenta: mito y realidad. Madrid: Ocho y Medio, 2008.

GETINO, Octavio; SOLANAS, Fernando. Hacia un tercer cine. Tricontinental, La Havana, n. 13, pp. 107-132, octobre 1969.

Cine, cultura y descolonización. Buenos Aires: Siglo XXI, 1973.

GUEVARA, Alfredo (dir.) Cine Cubano, La Habana, n. 68, 1971.

UAN-NAVARRO, Santiago. La primera carga al machete (Manuel Octavio Gómez, 1969). Cine, mito y revolución. In: AMIOT, Julie; BERTHIER, Nancy (dir.) Cuba: cinéma et révolution. Lyon: Le Grimh, 2006, pp. 105-113.

JOLIVET, Anne-Marie. Lucía (Humberto Solás, 1968). Trois Cubaines pour un renouveau révolutionnaire. In: AMIOT, Julie; BERTHIER, Nancy (dir.) Cuba: cinéma et révolution. Lyon: Le Grimh, 2006, pp. 85-93.

La ley no 169. Cinémas d'Amérique latine, Toulouse, n. 17, 2009, pp. 169-173.

LUSNICH, Ana Laura. El cine criollista-histórico. In: ESPAÑA, Carlos (dir.) Cine argentino, modernidad y vanguardias (1957-1983). Buenos Aires: Fondo Nacional de las Artes, 2005, pp. 410-419.

LUSNICH, Ana Laura; PIEDRAS, Pablo (ed.) Una historia del cine político y social en argentina (1896 - 1969). Buenos Aires: Nueva Librería, 2009. 
MARANGHELlO, César; PALADINO, Diana. San Martín en el cine. Representaciones del siglo XX. Cinémas d'Amérique latine, Toulouse, n. 18, 2010, pp. $28-40$.

OUBIÑA, Jorge. Veinte años de censura inconstitucional en el cine argentino (19631983). La censura en el cine hispanoamericano. Cuadernos de historia, crítica y teoría del cine, Buenos Aires, n. 1, 2004, pp. 69-85.

PARANAGUÁ, Paulo Antonio. Humberto Solás entre Oshum et Shangô. In: PARANAGUÁ, Paulo Antonio (dir). Le cinéma cubain. Paris: Centre Pompidou, 1990, pp. 141-151.

PERÓN, Juan Domingo. La hora de los pueblos. Madrid: Editorial Norte, 1968. Disponível em : <http://www.movimientoperonista.com/ficheros/LaHoradeLosPueblosPeron.pdf.>. Acceso em: 16 abr. 2012.

RAXHON, Philippe. San Martín: Un Libertador à l'affiche. In : JOSET, Jacques (ed.) Littérature, Histoire et Cinéma de l'Amérique Hispanique. Actes du Colloque International du Centre de Recherches et d'Etudes sur l'Amérique Ibérique, Université de Liège, Genève: Diffusion Librairie Droz, 2003, pp. 137-161.

SHOAT, Ella; STAM, Robert. Multiculturalismo, cine y medios de comunicación. Barcelona: Paídos, 2002.

SIGAL, Silvia. Le rôle politique des intellectuels en Amérique latine : La dérive des intellectuels en Argentine. Paris: L’Harmattan, 1996.

TAL, Tzvi. Pantallas y revolución: Una visión comparativa del cine de liberación y el cinema novo. Buenos Aires: Ediciones Lumiere, 2005.

SÁNCHEZ GONZÁLEZ, Jorge Luis. Romper la tensión del arco, movimiento cubano de cine documental. La Habana: Ediciones ICAIC, 2010.

Enviado em: agosto de 2012 e aprovado em: novembro de 2012.

Revista Eletrônica da ANPHLAC, n.14, p. 241-264, jan./jun. 2013.

http://revista.anphlac.org.br/index.php/revista 